\title{
Determining caregiver needs for respite, results of an Alabama survey
}

\author{
Brian Francis Geiger' ${ }^{1}$, Marcia R O' Neal $^{2}$ \\ 1. The Horizons School - Academic Affairs, Alabama, United States. 2. School of Education and Center for Educational \\ Accountability, University of Alabama at Birmingham, Alabama, United States.
}

Correspondence: Brian Francis Geiger. Address: The Horizons School - Academic Affairs, 2018 15th Avenue South, Birmingham, AL 35205, United States. Email: bgeiger@horizonsschool.org

Received: June 18, 2013

DOI : $10.5430 /$ jnep.v4n4p1
Accepted: September 16, 2013 Online Published: November 25, 2013

URL: http://dx.doi.org/10.5430/jnep.v4n4p1

\section{Abstract}

Background: The Alabama Lifespan Respite Resource Network ${ }^{\mathrm{TM}}$ enhances respite services for family caregivers with federal and state support. University evaluators assisted the Network to conduct a first statewide assessment of family caregivers using multiple formats (mail, in-person, online, phone). The purpose was to determine met and unmet needs for respite among families with relatives who have a disability or chronic illness. Results will be used to plan outreach education and match services to caregivers' needs.

Methods: A family caregiver survey was developed after reviewing professional literature and vetted with agency professionals and family caregivers. A total of 49 items were grouped into 4 general categories: service needs, demographics, caregiver expectations, and identification of service providers. State and local agencies serving children and adults with disabilities and chronic illness promoted caregiver participation and disseminated printed and online surveys statewide.

Results: Of 884 individuals completing the survey, 54\% provide daily care to a female with a disability or chronic illness and $52 \%$ of these were parents. Data indicated some family caregiver needs were met; however, $50 \%$ could not locate respite care at least once. Nearly $25 \%$ did not know how to request respite and worried about finding a qualified caregiver. Although 60\% reported less than $\$ 40,000$ annual income, only 20\% received a Medicare waiver. Caregivers' responses indicated 5 types of expectations for how respite services will help their family. The three most frequent types of expectations were attending to family caregiver's needs, helping with activities of daily living, and caring for others in my family. The two other expectations were providing financial assistance to pay for respite; and caregiver continuing education, providing therapies or medical treatment.

Conclusions: Respite services enable families to effectively care for relatives with disabilities and chronic conditions in communities. A majority of respondents to the Alabama survey who received respite praised its benefits and would feel stressed if respite was unavailable. Unfortunately, nearly half felt the most recent respite was insufficient to meet their needs, straining their caregiving capacity. Nurses and nurse educators have important roles to play, sharing information about respite services and providers with their patients, advocating for services to be provided to family caregivers, and participating in training paid and volunteer respite providers.

\section{Key words}

Caregiver stress and coping strategies, Respite, Assessment, Expectations, Disability 


\section{Introduction}

Promoting collaboration among federal, state and local agencies and organizations that fund or support respite is central to a successful Lifespan Respite Care Program. Such cooperative efforts enhance capacity and delivery of respite services for all family caregivers. Public Law 109-442 defines Lifespan Respite as "coordinated systems of accessible, communitybased respite services for all family caregivers of individuals with disabilities or chronic illness, regardless of age or special need" ${ }^{[1]}$.

The US Administration on Aging, the federal agency that administers the Lifespan Respite Care Program, guides states to collect baseline information, including demographics of family caregivers (age, residence, family size, income); specific respite care needs; and existing respite care services. A thorough assessment of needs and assets shall include capacity to provide respite care services to family caregivers; number and types of caregivers served; and coordination of respite care information and services within the state and localities.

According to federal law, 'family caregiver' means an "unpaid family member, a foster parent, or another unpaid adult, who provides in-home monitoring, management, supervision, or treatment of a child or adult with a special need" ${ }^{[1]}$. Caregivers attend to individuals with a wide array of needs and abilities, such as developmental disabilities and progressive physical illness. Each state and nonprofit agency determines eligibility to receive lifespan respite care according to rules established by federal, state and private funders. The National Alliance for Caregiving estimated 65.7 million people in the U.S. served as unpaid family caregivers to an adult or child in $2009^{[2]}$.

Funding provided to eligible state agencies enables Lifespan Respite Care Programs to: (a) identify existing respite resources and service gaps, (b) coordinate respite resources and providers, (c) create new respite services to address service gaps, (d) recruit and train qualified paid and volunteer respite providers, (e) provide public awareness information, and (f) empower caregivers by connecting them to respite resources and providers. This paper describes methodology and results for task (a) above in the state of Alabama.

According to the Work Group for Community Health and Development at the University of Kansas, "needs can be defined as the gap between what is and what should be" ${ }^{[3]}$. A needs assessment is the foundation to build a state Lifespan Respite Care Program. Effective planning of respite requires understanding caregivers' needs, perceptions and experiences. Caregiver data indicates needed improvements in respite services. For instance, respite planners in Alabama wish to know whether an online respite registry or database would be useful to families.

\section{Methodology}

The Alabama Department of Senior Services (ADSS) received a federal award enabling collaboration with the Alabama Lifespan Respite Resource Network ${ }^{\mathrm{TM}}$ (Respite Network). In Alabama, this Respite Network functions as the state Lifespan Respite Care Program. Respite Network members include state and nonprofit agency professionals, respite providers, and consumers. The purpose of the federal award is to plan and implement better access to respite resources for all Alabama family caregivers.

Evaluators from the University of Alabama at Birmingham (UAB) Center for Educational Accountability assessed needs of caregivers and their respite providers and monitored achievement of grant goals and objectives. Three goals guided the evaluation: (1) measure current capacity and improvement of the Respite Network as perceived by family caregivers, agencies, and providers; (2) identify needed enhancements to respite worker training and service delivery; and (3) identify facilitators and barriers to a coordinated system of lifespan respite care in Alabama ${ }^{[4]}$.

Evaluators collaborated with members of the state Respite Network and its Capacity Workgroup to develop two survey tools, and to invite family caregivers and agency service providers to participate. The focus of this paper is on methods and 
results of the first survey administered to family caregivers. Data revealed unmet needs for respite services. A parallel survey was administered to respite service providers.

We reviewed the helpful guide published by ARCH National Respite Network and Resource Center, Evaluating and Reporting Outcomes: A Guide for Respite and Crisis Care Program Managers ${ }^{[5]}$. Respite Network members and service providers offered suggestions about survey content and format during two public meetings, and by Email and telephone messages. Items were developed to assess caregiver quality of life in response to concerns expressed by members of the Respite Network. Consistent with the Stress Process Model of Caregiving, family caregivers prioritize loved ones' immediate needs before their own. Short-term respite care may ameliorate primary (disabilities and limitations) and secondary (role demands, anxiety, depression) stressors among caregivers ${ }^{[6-8]}$.

The Survey of Family Caregivers about Respite Services contains 49 items, of which eight require open-ended responses. Items were grouped in general categories: respite service needs and history of use (28 items); demographics (13 items); caregiver expectations and precipitating events (5 items); and identification of service providers and agency referrals (3 items). Estimated length of time to complete the survey is 30 minutes. Content validity was established by Respite Network members, respite service providers, and the federal project officer, who provided guidance throughout survey development. In addition, a small group of 7 respite providers and family caregivers responded to the draft survey, indicating needed improvements to content and format. Edits were made before administering the survey to family caregivers.

Agency representatives invited primary family caregivers eligible for respite to participate anonymously in the needs assessment through established service contacts. Some caregivers had received respite, while others were eligible but had not benefited from this service at the time of the survey. The survey was provided in different formats (printed and online forms), enabling many caregivers to participate. Family caregivers with questions about the survey called the evaluators for assistance. Several caregivers chose to respond to items by phone. All responses received by telephone were entered in the database.

Five agencies posted announcements plus links to the online survey on homepages, and two agencies included announcements about the survey in newsletters distributed statewide. Several agencies including Area Agencies on Aging distributed printed forms and information sheets during support group and training events for family caregivers. These methods protected privacy of individuals as university researchers did not receive lists of caregiver names and contact information.

Informed consent was not required. No family caregiver was obligated to participate in the statewide assessment. Those who declined to do so did not suffer penalties. Those who wished to discontinue participation did so without adverse consequence. Those who desired physical assistance to participate requested this from an agency represented on the statewide Respite Network or the project evaluators. The UAB Institutional Review Board for Human Use granted expedited approval for survey protocol. Responses to survey items were combined into a single Excel file and analyzed with descriptive statistics (frequencies and percentages).

\section{Results}

Data collected in Alabama is presented and compared to data from a national survey administered by AoA, the federal agency which funds Lifespan Respite Care Programs across the country and which paid for this needs assessment in Alabama. A total of 943 individuals attempted and 884 completed a majority of items. Not all completers responded to every item, so the total number of responses differ by item. All available responses are included in the results and compared to data obtained from a national sample of caregivers who responded to similar items. 
Most (87\%) of Alabama participants were females, greater than the $76 \%$ of caregivers who used Older American Act (OAA) caregiver services in a similar national study ${ }^{[9]}$. The average age of Alabama caregivers was 50.8 years, higher than the average age (41.5 years) of the national sample. Two thirds (67\%) of caregivers who completed the Alabama survey were Caucasian, and nearly one third (32\%) were African American. This compares to 87\% Caucasian caregivers, 10\% African American, 3\% Hispanic, and 3\% Asian caregivers nationwide who used OAA programming.

Slightly more than half (52\%) of Alabama respondents were birth or adoptive parents of the person with a disability or chronic illness. Just over $25 \%$ of respondents were the son or daughter. A total of $54 \%$ of participants provided daily care for a female with a disability or chronic illness. In Figure 1 are responses from 839 caregivers who responded to the item, How much assistance does the person with a disability or chronic illness require? The most common response (56\%) was continuous assistance, followed by frequent assistance (25\%).

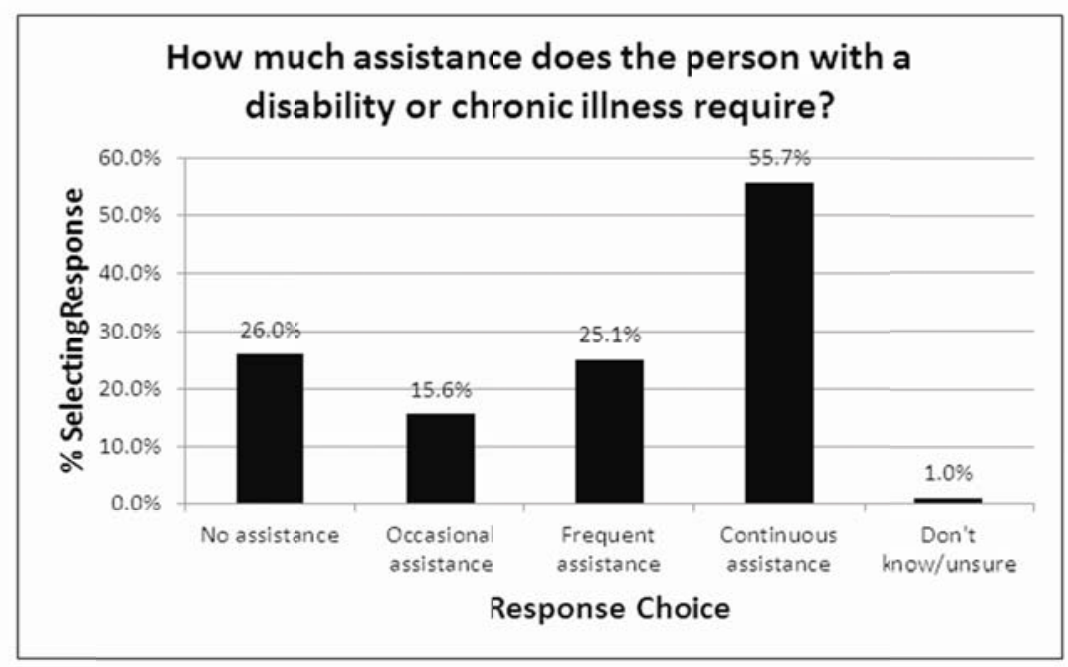

Figure 1. Assistance Required by Relative with a Disability or Chronic Illness ( $\mathrm{n}=839)$

A majority (64\%) of Alabama participants were married, $16 \%$ were single, and $10 \%$ were divorced. Fewer Alabama caregivers were married and twice as many were single as in the nationwide sample. Three fourths (76\%) reported annual family income of $\$ 60,000$ or less, and $60 \%$ earned $\$ 40,000$ or less annually. Annual incomes reported by caregivers are approximately similar between the Alabama and nationwide samples ${ }^{[9]}$.

Only 20\% reported receiving a Medicaid waiver for caregiver respite services. Two thirds (69\%) of respondents had never accessed caregiver respite services using a Medicaid waiver. At least 13\% did not know if they had received waivers.

Results included solicited comments to qualitative survey items, providing an in-depth understanding of family caregiver needs of respite services. The following comment from a caregiver highlights the perceived value of respite.

Without the respite services, I would be in a mental hospital and my family would have fallen apart. My respite caregiver is a lifesaver and she loves my child. She only gets paid 8.00 an hour, though, and has three children of her own (single mom) and needs to find a job where she can earn more money - Alabama family caregiver

A total of 690 caregivers responded to the item asking about how respite services will help their family. Responses were grouped into 5 themes for analysis: 1) attending to family caregiver's needs; 2) helping with activities of daily living (ADL); 3) caring for others in the family; 4) providing financial assistance to pay for respite; and 5) caregiver continuing education, providing therapies or medical treatment (listed in rank order). Many responses included multiple caregiver expectations for respite benefits. Representative responses from families illustrate frequent expectations of respite care: 


\section{Attending to family caregiver's needs}

- $\quad$ Reduce stress by allowing relief from the constant responsibility of caring for a person with a disability.

- It allows me time to renew with a break. My child also loves the break!

\section{Helping with activities of daily living}

- Respite services are provided so that a caregiver may attend to other areas of his or her life during the respite period, for example, grocery shopping or taking another child to a movie.

- $\quad$ Respite allows me to work and care for my mother. With respite, I'm able to visit my children and friends, to go shopping, and to participate in other activities.

\section{Caring for others in the family}

- Give me the time to get out and do things with my other child.

- Gives me time to spend with my husband, sons, daughters-in-law and seven grandchildren, as well as providing me some time for myself.

\section{Providing financial assistance to pay for respite}

- Helps me to pay someone to stay with my loved one while I work.

- They paid for someone to sit with my son for 10 hours. - I got a good break. I did not have enough income on my own to pay for this service.

\section{Caregiver continuing education, providing therapies or medical treatment}

- It helps me by letting me know how and what kind of exercise to do with my son to help him get better.

- To give me opportunities to attend conferences to learn more about helping my child...

Events that led to the most recent request for respite care services were identified by 858 family caregivers who responded to the item. The 4 most common responses were to "relieve stress" (73\%), "care for myself" (46\%), "care for personal business" (31\%), and "improve relationship with my spouse or partner" (30\%). Some caregivers may be reluctant to request assistance.

More than 650 family caregivers responded to the open-ended item, "Tell how members of your household were affected by the event leading to the most recent request for respite services." Selected quotes from family caregivers represent the types of responses to this completion item.

\section{Relieve family caregiver stress}

- Not having time to relieve stress of daily life, leads to more stress, which in turn, leads to not being able to function properly as a parent and caregiver.

- I recently was laid off from work, and am acting as his full-time caregiver; it is difficult for me to search for work, interview, etc. I can go nowhere without him, and he has a very difficult time seeking help from anyone but me. I enjoy caring for him, but I still need an income. 


\section{Care for myself}

- I want to make sure she is safe and so I can care for myself.

- Without help, sometimes my family members stress me out. I don't have time to care for myself...(I am) looking out for my husband's safety when I have to leave him alone.

\section{Care for personal business}

- Well, it frees me up to take care of personal business that only I can take care of. Also, it helped me deal with some anger issues and a lot of depression over my loss.

- I can pick up a granddaughter from school, run errands. (I) couldn't cook supper here alone with (my loved one for whom I care).

- He has someone to sit with him while I run my errands or get some rest.

\section{I mprove relationship with my spouse or partner}

- I feel like I neglect other members because all I do is work and take care of my mom. My daughter has Type 1 diabetes and she needs my help too.

- (Respite) improved my relationship with my spouse by giving us time with each other.

- Spouse benefits (from respite) as we are able to be away and recipient is being cared for.

In Figure 2 are responses from 843 family caregivers who indicated the outcome of the most recent application for caregiver respite services. Almost half (48\%) received respite services in their home. Only $8 \%$ of respondents received respite services in an agency or community setting. More than one-fourth (28\%) either did not receive family caregiver respite services or were either placed on a waiting list. Examination of responses to the "other" category (23\%) revealed that these family caregivers do not know how to request respite services and are concerned about finding a qualified caregiver.

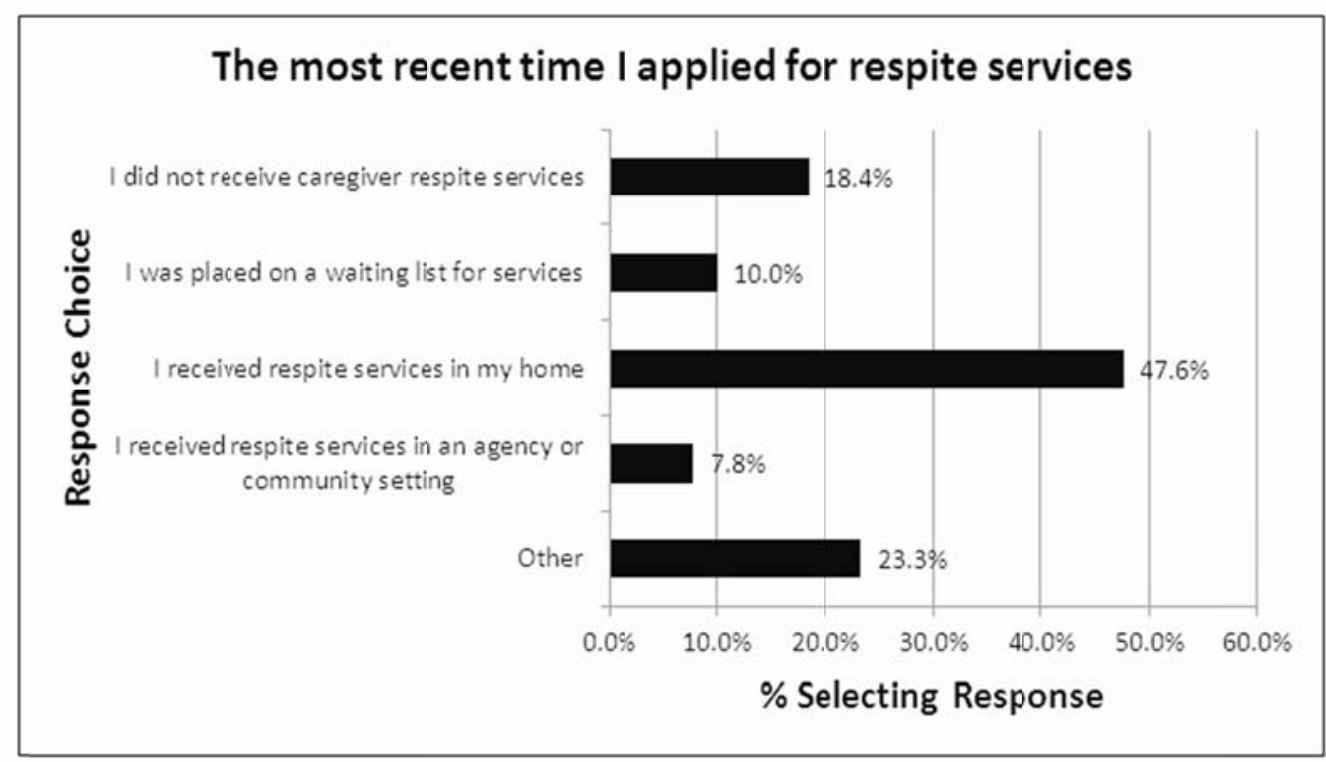

Figure 2. Percentage of Caregivers Selecting Each Outcome of their Most Recent Respite Application $(n=843)$ 
Of 754 family caregivers, 32\% were unable to find caregiver respite services when needed on 3 or more occasions. Another 9\% could not find respite services on 2 occasions when needed. The same number could not find respite services on one occasion when needed. Among the 819 respondents who answered a related question, the majority (74\%) are not on a waiting list for caregiver respite services.

Of 779 respondents, 39\% indicated that the most recent caregiver respite service lasted for one day or less. Another $8 \%$ of caregivers received 2 days of respite services and $18 \%$ received 3 or more days of respite services. Among 743 caregivers who responded to an item about length of services, $45 \%$ said the most recent respite service was not enough to meet their needs. A total of 785 caregivers replied to the item, "how would you feel if caregiver respite services were not available?" The most frequent response among caregivers was extremely stressed (54\%), followed by moderately stressed (24\%).

Figure 3 reveals Alabama caregivers learned about respite services from one or more contacts. They most frequently learned from friends and relatives (24\%), agencies (22\%), clinicians (18\%), and support groups (15\%). Less frequently they learned from web sites (10\%) and church or faith organizations (4\%). In addition, $28 \%$ of caregivers named a variety of other service providers, programs, meetings and media.

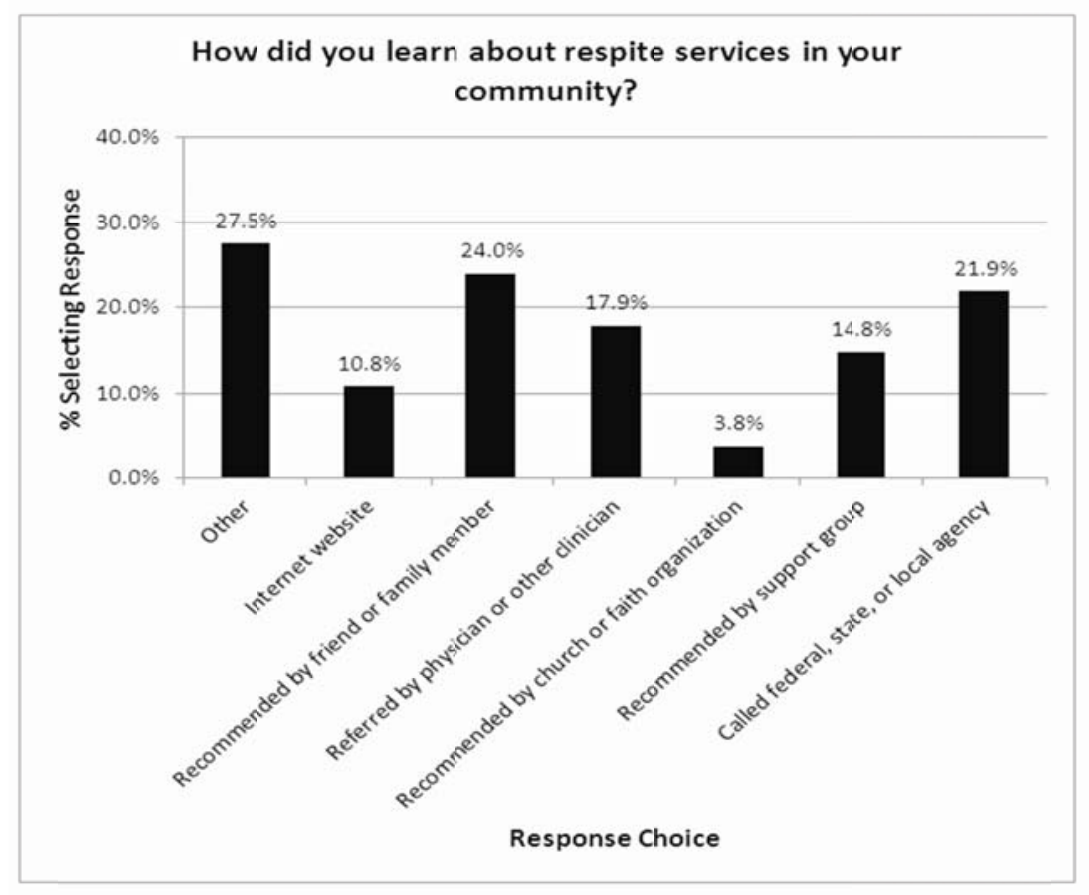

Figure 3. Number and Percentage of Caregivers Indicating How They Learned About Respite $(\mathrm{n}=800)$

Between 823 and 843 family caregivers indicated levels of difficulty (much, some, none) for 10 life skills among relatives with disabilities or chronic illness as shown in Figure 4. These life skills correspond to ADL. At least half of caregivers perceived much difficulty for transportation (62\%), cooking (59\%), taking medication (57\%), and personal hygiene (55\%). Feeding was least often perceived as a difficult skill. Almost one fifth (18\%) of Alabama family caregivers responded other, and explained that their loved one needs constant care or has sensory disabilities. Representative quotes from caregivers illustrate needs:

- My daughter has cerebral palsy and is wheelchair bound and cannot verbally tell you what she needs. She needs constant supervision and help to do normal activities, such as toileting and feeding.

- He requires total care. 
- $\quad$ She is totally dependent (on care from others).

Finally, 477 caregivers offered additional comments concerning respite care that were grouped into four categories: Benefits to the Caregiver and Family Members; Unmet Needs for Respite; Awareness about Respite; Confidence and Trust in the Respite Provider. Selected comments from family caregivers represent their thoughts and needs.

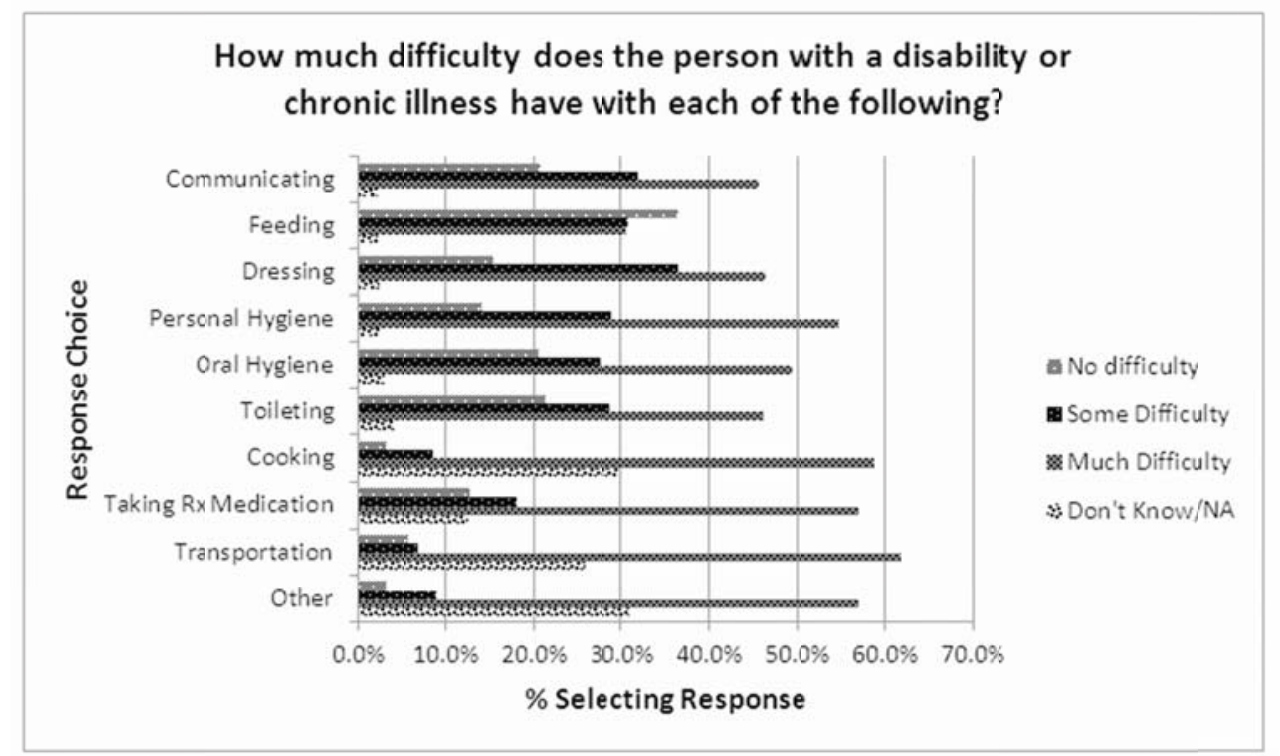

Figure 4. Caregivers’ Perceptions of Difficulty Level with Life Skills among Persons with Disabilities and Chronic Illness

$$
(\mathrm{n}=855)
$$

\section{Benefits to the caregiver and family members}

- $\quad$ Respite services for the caregiver are very important. One person cannot handle ‘around the clock' care.

- $\quad$ It enables families to keep their children at home instead of placing in nursing homes due to total care needs.

- $\quad$ They are needed so family members can stay at home and it improves the health of the caregiver.

\section{Unmet needs for respite}

- $\quad$ Respite services being received are extremely helpful, but we could certainly use more hours of care and more flexibility...The individual for whom services are authorized requires continuous care and supervision.

- $\quad$ As aging parents, we have the need for respite care on a continual basis. We have to make arrangements far ahead of actual dates that we need respite. Our schedule has to be arranged around the needs of our child...

- It would be very helpful if assistance was provided on need vs. hours. It would be nice to have someone fill in as a companion as well as giving help to a patient. It is very difficult if you do not have the finances to hire the help you need.

\section{Awareness about respite}

- $\quad$ I have never been given a list for caregivers. I have to find my own...

- $\quad$ I've never been offered such services, but I would be very grateful for any help offered. 
- I would like to find out how to apply for respite care services in my area.

- We need more information on where we can receive respite money or services.

\section{Confidence and Trust in the Respite Provider}

- It would be great to have any qualified respite services. I don't need people here who are not trained or who don't want to be here.

- It'd be nice to know there was a qualified caregiver who'd passed a background check that you felt confident was safe. I feel I would benefit from having respite 5 or more hours a week...

- I need access to a safe place whereby if I have to go out of town I know that my child can be left there and be well taken care of.

\section{Conclusions}

The federal Public Health Act (Public Law 109-442) was amended in 2006 permitting eligible state agencies to receive support for respite services across the lifespan to "(i) to develop or enhance lifespan respite care at the State and local levels; (ii) to provide respite care services for family caregivers caring for children or adults; (iii) to train and recruit respite care workers and volunteers; (iv) to provide information to caregivers about available respite and support services; and (v) to assist caregivers in gaining access to such services" ${ }^{[1]}$. The anticipated outcome of respite is enabling families to care for relatives with disabilities and chronic conditions in communities, reducing need for institutional care ${ }^{[10]}$.

A total of 884 family caregivers responded to printed and online survey forms indicating respite capacity, services provided and unmet needs. A majority of family caregivers who received respite services were very pleased and indicated expectations about respite benefits. Caregivers in Alabama anticipate relief from caregiving burdens, assistance with ADL, care provided to others in the family, financial assistance to pay for respite, continuing education, and therapies, or medical treatment. Similar to results of other research about "dignified care" ${ }^{[10,11]}$, these caregivers articulated a desire for competent and responsive providers who respect caregivers, handle difficult behaviors, facilitate autonomy and empowerment among relatives with disabilities and chronic illness.

Expectations about respite benefits among Alabama caregivers may be compared to a national sample of caregivers ${ }^{\text {[12] }}$. Specifically, 4 service needs were identified among 833 dementia and non-dementia caregivers who responded to the item. Needs included: (a) keeping the person I care for safe at home (37.3\%), (b) finding time for myself (36.5\%), (c) balancing my work and family responsibilities (31.2\%), and (d) managing my emotional and physical stress (31.0\%).

Results from the survey of Alabama family caregivers may be compared to a qualitative study of family caregivers in Australia. Among Australian caregivers, some were reluctant to use respite due to normative expectations that they must always care for their spouse with dementia ${ }^{[10]}$. Concerns about trust in the skills of the respite provider among Alabama caregivers were similar to results reported from interviews of Canadian caregivers and clients over age 65 who received in-home care services. Canadian participants qualified characteristics of adept versus inept staff as these affect program satisfaction. Interviews revealed family concerns about predictable versus precarious scheduling affecting participant satisfaction. Providers did not always adhere to expected schedules and were not always available when needed. In addition, agencies chose different persons to provide home care for the same individual ${ }^{[13]}$.

Caregiver preference for in-home care may indicate multiple challenges preparing a relative with a disability or chronic illness for transport to a community setting ${ }^{[10]}$. Over three fourths (81\%) of Alabama respondents said their family member with a disability or chronic illness required frequent or continuous assistance and could not be left unattended for 
long periods. The same number would feel stressed if caregiver respite was not available. Review of similar research indicated caregiver frailty and personal discomfort as reasons to request help with ADL for relatives with dementia ${ }^{[10]}$.

Despite progress made since receipt of federal funding, there are unmet needs for caregiver respite in Alabama. Many family caregivers in this statewide sample would find it difficult to bear the expense of respite without assistance from state and nonprofit agencies. Nearly half who received respite said the most recent service was insufficient to meet caregiver needs. Some family caregivers could not find respite services when needed, i.e. more than 200 could not find respite on three or more occasions, and 65 could not find respite on two occasions. Waiting for a needed service may strain existing caregiver capacity ${ }^{[10]}$, leading to burnout and use of emergency, acute and long-term care facilities ${ }^{[8]}$.

Through outreach, the Alabama Respite Network is increasing awareness. Consumer education topics include navigating health and social service systems, choosing qualified respite providers, and caregiver support. To increase recipient satisfaction, family caregiver training should include frank discussion about roles and limitations of the respite provider. In addition, the state Respite Network has implemented Sharing the Care training programs for respite providers, building capacity within communities ${ }^{[8]}$. Training for providers includes responding to actual needs of caregivers within rules established by the program and requesting additional assistance when needed. Anticipated outcomes of successful training programs are enhancing consumer confidence and satisfaction and preparing providers to offer needed services ${ }^{\text {[13] }}$.

Nurses and nurse educators have important roles to play, guiding decisions about caregiving and healthcare, including managing medications, supervising personal and social behavior, treating illness symptoms, and seeking care from specialists. Families trust advice and referrals about respite services and providers from clinicians, who may also teach how to perform instrumental activities of daily living for relatives with disabilities and chronic conditions. Nurses may encourage caregivers to increase their specific health knowledge, seek social support to lessen caregiver strain, and understand legal and financial issues ${ }^{[14]}$.

Results of a statewide survey will enable Respite Network members and health service providers to more accurately identify respite needs, services available to family caregivers and indicate areas for improvement. The Respite Network presented highlights of survey methodology and results during its 2012 Legislative Awareness Day held at the statehouse. Data was useful to inform legislators about the needs of family caregivers and advocate for new state and federal resources. For instance, highlights of the needs assessment substantiated a subsequent federal award to further implement the statewide respite program. Targeted activities for 2013-15 include developing a directory of respite care providers by county, coordinating respite services across state and nonprofit agencies, expanding capacity of a respite referral service for consumers, and increasing training for respite volunteers (especially through faith-based organizations).

\section{Acknowledgements}

This project was funded by the U.S. Administration on Aging, HHS-2009-AOA-LR-0916, through an award to the Alabama Department of Senior Services. Authors greatly appreciate contributions from the members of the Alabama Lifespan Respite Resource Network ${ }^{\mathrm{TM}}$.

\section{References}

[1] Public Law 109-442-DEC. 21, 2006120 STAT. 3291. http://www.gpo.gov/fdsys/pkg/PLAW-109publ442/pdf/PLAW-109publ442.pdf

[2] National Alliance for Caregiving. 2009, November. Caregiving in the U.S. http://www.caregiving.org/data/CaregivingUSAllAgesExecSum.pdf

[3] Work Group for Community Health and Development at the University of Kansas. 2011. The community toolbox: Bringing solutions to light. Part B. Community assessment, agenda setting, and choice of broad strategies (Chapters 3-5). http://ctb.ku.edu/en/tablecontents/index.aspx\#b 
[4] Geiger, B.F., \& O’Neal, M.R. 2011, Jan. 14. Results from the statewide needs assessment of family caregivers and respite service providers. Scientific Seminar Series, University of Alabama at Birmingham Center for Aging and Veterans Administration Geriatric Research Center and Clinical Centers, Birmingham, AL.

[5] ARCH National Respite Network and Resource Center. 2002. Evaluating and reporting outcomes: A guide for respite and crisis care program managers, (2nd Ed.). Author: Chapel Hill, NC.

[6] Pearlin, L.I., Mullan, J.T., Semple, S.J., \& Skaff, M.M. 1990. Caregiving and the stress process: An overview of concepts and their measures. The Gerontologist, 20, 583-594. http://dx.doi.org/10.1093/geront/30.5.583

[7] Mensie, L.C., \& Steffen, A.M. Depressive symptoms and use of home-based respite time in family caregivers. Home Health Services Quarterly. 2010; 29(3): 120-137. PMid:20845174 http://dx.doi.org/10.1080/01621424.2010.511514

[8] Jansen, L., Forbes, D.A., Markle-Reid, M., Hawranik, P., Kingston, D., Peacock, S., Henderson, S., et al. Formal care providers' perceptions of home- and community-based services: Informing dementia care quality. Home Health Care Services Quarterly. 2009; 28(1): 1-23. PMid:19266368 http://dx.doi.org/10.1080/01621420802700952

[9] Beauchamp, J., \& Trebino, L. 2008, March. Results from the Administration on Aging's third national survey of Older Americans Act program participants - Final report. http://www.mathematica-mpr.com/publications/PDFs/AdminAgingSurvey.pdf

[10] Phillipson, L., \& Jones, S.C. Between the "Devil and the Deep Blue Sea": The beliefs of caregivers of people with dementia regarding the use of in-home respite services. Home Health Care Services Quarterly. 2011; 30(2): 43-62. PMid:21590565 http://dx.doi.org/10.1080/01621424.2011.569522

[11] Li, H. 2011. Unmet service needs: A comparison between dementia and non-dementia caregivers. Home Health Services Quarterly. 2012; 31(1): 41-59. PMid:22424306 http://dx.doi.org/10.1080/01621424.2011.641921

[12] Byrne, K., Sims-Gould, J., Frazee, K., \& Martin-Matthews, A. “I’m Satisfied...But”: Clients’ and families’ contingent responses about home care. Home Health Care Services Quarterly. 2011; 30(4): 161-177. PMid:22106900 http://dx.doi.org/10.1080/01621424.2011.622242

[13] Arino-Blasco, S., Tadd, W., \& BoixFerrer, J.A. Dignity and older people. Quality in Ageing. 2005; 6(1):30-36. http://dx.doi.org/10.1108/14717794200500006

[14] Skinner, K. Nursing interventions to assist in decreasing stress in caregivers of Alzheimer's patients. ABNF Journal. 2009; 20(1): 22-4. 